\title{
Executive Functioning in Adults with Down Syndrome: Machine-Learning-Based Prediction of Inhibitory Capacity
}

\author{
Mario Fernando Jojoa-Acosta ${ }^{1}\left(\right.$, Sara Signo-Miguel ${ }^{2}$, Maria Begoña Garcia-Zapirain ${ }^{1}($, \\ Mercè Gimeno-Santos ${ }^{2}\left(\mathbb{D}\right.$, Amaia Méndez-Zorrilla ${ }^{1}$ (D) Chandan J. Vaidya ${ }^{3}$, Marta Molins-Sauri ${ }^{2}$ (D), \\ Myriam Guerra-Balic ${ }^{2}$ and Olga Bruna-Rabassa ${ }^{2, *}$ \\ 1 eVIDA - Lab, Faculty of Engineering, Deusto University, 48007 Bilbao, Spain; \\ mariojojoa@deusto.es (M.F.J.-A.); mbgarciazapi@deusto.es (M.B.G.-Z.); amaia.mendez@deusto.es (A.M.-Z.) \\ 2 Faculty of Psychology, Education and Sports Sciences Blanquerna, Ramon Llull University, 08022 Barcelona, \\ Spain; sarasm0@blanquerna.url.edu (S.S.-M.); mercegimenos@blanquerna.url.edu (M.G.-S.); \\ MartaMS6@blanquerna.url.edu (M.M.-S.); myriamgb@blanquerna.url.edu (M.G.-B.) \\ 3 Department of Psychology, Georgetown University, Washington, DC 20057, USA; cjv2@georgetown.edu \\ * Correspondence: olgabr@blanquerna.url.edu
}

check for

updates

Citation: Jojoa-Acosta, M.F.; Signo-Miguel, S.; Garcia-Zapirain, M.B.; Gimeno-Santos, M.;

Méndez-Zorrilla, A.; Vaidya, C.J.; Molins-Sauri, M.; Guerra-Balic, M. Bruna-Rabassa, O. Executive Functioning in Adults with Down Syndrome: Machine-Learning-Based Prediction of Inhibitory Capacity. Int. J. Environ. Res. Public Health 2021, 18 , 10785. https://doi.org/10.3390/ ijerph182010785

Academic Editors: María Teresa García Ordás, José Alberto Benítez Andrades and Jose Luis Calvo-Rolle

Received: 29 July 2021

Accepted: 5 October 2021

Published: 14 October 2021

Publisher's Note: MDPI stays neutral with regard to jurisdictional claims in published maps and institutional affiliations.

Copyright: (c) 2021 by the authors. Licensee MDPI, Basel, Switzerland. This article is an open access article distributed under the terms and conditions of the Creative Commons Attribution (CC BY) license (https:// creativecommons.org/licenses/by/ $4.0 /)$.

\begin{abstract}
The study of executive function decline in adults with Down syndrome (DS) is important, because it supports independent functioning in real-world settings. Inhibitory control is posited to be essential for self-regulation and adaptation to daily life activities. However, cognitive domains that most predict the capacity for inhibition in adults with DS have not been identified. The aim of this study was to identify cognitive domains that predict the capacity for inhibition, using novel data-driven techniques in a sample of adults with DS ( $n=188 ; 49.47 \%$ men; $33.6 \pm 8.8$ years old), with low and moderate levels of intellectual disability. Neuropsychological tests, including assessment of memory, attention, language, executive functions, and praxis, were submitted to Random Forest, support vector machine, and logistic regression algorithms for the purpose of predicting inhibition capacity, assessed with the Cats-and-Dogs test. Convergent results from the three algorithms show that the best predictors for inhibition capacity were constructive praxis, verbal memory, immediate memory, planning, and written verbal comprehension. These results suggest the minimum set of neuropsychological assessments and potential intervention targets for individuals with DS and ID, which may optimize potential for independent living.
\end{abstract}

Keywords: aging; artificial intelligence; cognition; Down syndrome; executive functions; feature selection; inhibition; machine learning; neuropsychology

\section{Introduction}

Longer life expectancy in people with Down syndrome (DS), often into the fifties, and high rates of cognitive decline have led to a growing interest in the study of their aging process [1-7]. and in ways to encourage healthy aging [8-11]. Patterns of cognitive changes during aging in adults with DS are diverse $[12,13]$ but most severely affect memory, language, visuoconstructional skills, executive functions, and motor praxis skills [14-20]. Furthermore, a greater predisposition to develop Alzheimer's disease (AD) [21-24] has been noted, with onset of dementia marked by declines in episodic memory, visuospatial organization, visuospatial memory, and executive functions [25]. Importantly, alteration in executive functions has been recognized as one of the first symptoms of $\mathrm{AD}$ in persons with DS. Therefore, assessment and understanding of these functions in adults with DS is critical for early diagnosis of $\mathrm{AD}$ and a better quality of life [26]. Executive function $(\mathrm{EF})$ is a multidimensional construct that includes self-regulatory processes of response inhibition, working memory, and cognitive flexibility [27]. Among the general population, good executive function performance in the early stages of life predicts positive outcomes in adulthood, including better social relationships, higher levels of employment, and fewer 
risky behaviors $[28,29]$. Together with other cognitive functions, response inhibition in particular has been singled out as a process that promotes cognitive performance that is adaptive to one's environment [30]. In the adult population with DS, changes in executive functions (EF) are characterized by difficulties with working memory, sustained attention, planning, and inhibition [31]. An age-related decline in executive functions has also been observed in connection with verbal working memory and visuospatial planning such that a decline in inhibition capacity and cognitive flexibility precedes that in verbal/visuo-spatial memory [32-36]. Improvement has been noted in the affected executive functions such as working memory, inhibition, and planning after using neuropsychological intervention programs [26]. Longitudinal studies in adolescents with DS and intellectual disability (ID) indicate significant changes in planning tasks, verbal fluency, and short-term memory in 3-to-5-year longitudinal monitoring. However, persons with ID are distinctive for inhibition control deficits $[32,33,37]$. Difficulties are evident in tasks that require simultaneous attention, short-term verbal memory, and working memory, leading to poorer performance in adults over 50 [37]. Other studies focusing on persons with DS reveal an age-related decline in verbal working and visuospatial memory in addition to mental flexibility $[34,35,38]$. They also suggest a greater decline in comparison to persons with ID due to other etiologies in planning, attention, and verbal fluency $[39,40]$. Verbal intrusions associated with executive functions have been observed in middle-aged adults with DS [31-33]. A positive correlation between inhibition capacity (measured by the Cats-and-Dogs test) and visual memory (measured by object memory) has been observed. Other studies have shown a significant correlation between age and planning capacity, long-term selective memory and receptive language [41]. Thus, executive function impairment co-occurs with a decline in memory skills in persons with DS. Autonomy and quality of life factors have increased for persons with DS in recent years as a result of the support they have received in adapting to the working world. However, fewer persons with DS are hired due to their EF deficits [42]. Understanding and training EF performance could increase the quality of life for people with DS and also improve patterns related to inhibition control and self-regulation [26,43]. Different studies suggest that practical skills, referred to as daily tasks, are a strength for people with DS since they often remain stable as they age [43]. However, their EF deficits cause them to experience difficulty in successfully managing certain daily situations [43]. Furthermore, when persons with DS have dementia caused by $\mathrm{AD}$, they undergo a marked decline in their overall functioning because it is a progressive condition and therefore seriously impacts their quality of life. For this reason, it is important to find out more about EF in persons with DS in order to improve their quality of life and autonomy [26]. In summary, further study is needed on EF decline in aging adults with DS [44], considering that the role of these higher cognitive functions is to control and regulate cognitive skills. It has also been suggested that early clinical detection of $\mathrm{AD}$ in persons with $\mathrm{DS}$ coincides with executive deficits. The results indicate that the general population manifests short-term memory decline as the most common indicator associated with AD onset, whereas persons with DS normally show executive dysfunction and behavioral and psychological symptoms in the preclinical stages, which may precede loss of memory [45]. Furthermore, it has been suggested that one indicator of $\mathrm{AD}$ in persons with DS is loss of daily living skills [46] and that they are more affected as they grow older [47]. On the one hand, boosting their cognitive reserve is vital. This may be achieved through interventions in their school and work environments and could help to reduce the cognitive decline associated with dementia $[48,49]$. In light of the importance of executive function to adaptive outcomes and their co-occurrence with memory and other cognitive deficits, we aimed to identify cognitive factors that predict inhibition capacity in adults with DS. The application of machine learning algorithms was chosen for this study, as they are widely used to identify the role of features and/or variables when searching for specific behavior of a certain phenomenon. This is generally achieved through training and testing supervised predictive models that recognize relational patterns between a response variable and some input variables. As a result, the necessary procedure focuses on training 
three predictors, and based on their implicit metrics, determining which of all the input variables involved have the greatest impact on the behavior of the dependent variable (inhibition capacity). The algorithms used are Random Forest, logistic regression [50], and support vector machines, and they were selected for their widespread scientific use in this type of application. Furthermore, the intersection of sets is proposed as the ensemble method for the results obtained by each algorithm, as well as weight-based organization in order to normalize the results between the three models used.

The research objective is to apply artificial intelligence techniques to analyze the cognitive performance results collected in previous studies on the adult population with DS in order to identify the variables with the greatest impact on improving cognitive performance in everyday activities in the aging process.

\section{Materials and Methods}

\subsection{Materials: Data Description}

The data analyzed were obtained from a cross-sectional study [51]. The participants were recruited through intentional non-probabilistic sampling. The sample consisted of 188 adults with DS who evidenced mild or moderate ID. The participants were recruited from 26 Spanish and South American institutions and foundations for the care of persons with ID. They agreed to participate in this study on a voluntary basis. The confidentiality of the data for the present study has been preserved at all times. Family members and the participants themselves have signed informed consent forms, in compliance with Organic Law 15/1999 on Personal Data Protection and the application of Law 41/2002 on Basic Regulation of Patient Autonomy and Rights and Obligations in terms of information and clinical documentation. Furthermore, article 27 of the Helsinki Declaration [52] has been observed. It regulates the criteria for the publication of research results.

Inclusion criteria for the sample are being an adult (over 18 years of age) with DS, of either sex, and that the participants and their legal representatives have signed the informed consent form. Persons with a diagnosis of a neurological, neurodegenerative, or severe mental illness that could significantly interfere with the test results were not eligible to participate. Persons who had been diagnosed with non-disability-related physical and/or cognitive changes and had severe sensory impairment were also excluded.

The ages of the study participants range from 19 to 62 years, with an average age of $33.63(\mathrm{SD}=8.81)$. The sample includes $93(49.47 \%)$ men and $95(50.53 \%)$ women.

\subsection{Research Instruments}

Overall cognitive performance assessment of the participants is particularly important due to the wide diversity of cognitive skills in the population with DS. Raven's Colored Progressive Matrices test was used for the assessment of intellectual function [53].

Cognitive assessment included 21 tests selected from different neuropsychological batteries that have been validated for the Spanish population, in addition to ad hoc measures created for assessing orientation to time, place, or person. As the population under study was formed by persons with DS, experts were consulted to obtain evidence of the validity, concordance, and relevance of the cognitive assessment tests based on their content. The set of 21 tests was satisfactorily validated for content by the experts [51]. Table 1 shows the selected tests for assessment of the following cognitive domains: memory, attention, language and communication, executive functions, and praxis. 
Table 1. Neuropsychological tests to perform the cognitive assessment of adults with DS [51].

\begin{tabular}{|c|c|c|}
\hline Cognitive Domains & Instruments & Acronyms of Variables Names \\
\hline General cognitive performance & $\begin{array}{c}\text { Scale color progressive matrices of } \\
\text { RAVEN (RCPM) [53] }\end{array}$ & Raven \\
\hline $\begin{array}{l}\text { Memory (immediate, verbal memory, } \\
\text { visual memory and visual recognition } \\
\text { memory) }\end{array}$ & $\begin{array}{l}\text { Memory of images (ad hoc) } \\
\text { Image recognition (ad hoc) } \\
\text { Verbal Memory 1a and } 1 \mathrm{~b}[54]\end{array}$ & $\begin{array}{l}\text { Mem_ima } \\
\text { Mem_recog } \\
\text { Mem_verbal }\end{array}$ \\
\hline $\begin{array}{c}\text { Attention (attention and verbal } \\
\text { short-term memory) }\end{array}$ & Direct digits (K-ABC) [55] & Direct_D \\
\hline $\begin{array}{l}\text { Language and communication (receptive } \\
\text { vocabulary, denomination, spontaneous } \\
\text { language and verbal fluency) }\end{array}$ & $\begin{array}{c}\text { Peabody Picture Vocabulary Test (PPVT) } \\
\text { [56] } \\
\text { Visio-verbal denomination (ad hoc) } \\
\text { Spontaneous language: description of a } \\
\text { sheet [57] } \\
\text { Verbal fluency: categorical evocation [58] } \\
\text { Oral verbal comprehension (ad hoc) } \\
\text { Written verbal comprehension [57] }\end{array}$ & $\begin{array}{c}\text { PPVT } \\
\text { Total_denomin } \\
\text { Spont_lang } \\
\text { Verbal_flu } \\
\text { OV_compr } \\
\text { WV_compr }\end{array}$ \\
\hline $\begin{array}{l}\text { Executive functions (executive function, } \\
\text { processing speed, planning and motor } \\
\text { execution) }\end{array}$ & $\begin{array}{l}\text { Cats-and-Dogs test [31,59] } \\
\text { Clock test [60] } \\
\text { Motor execution } 1 \\
\text { Motor execution } 2 \\
\text { Overall motor execution [57] } \\
\text { Mental control—numbers } \\
\text { Mental control—days } \\
\text { Overall mental control [57] }\end{array}$ & $\begin{array}{c}\text { EF } \\
\text { Clock_order // Clock_copy } \\
\text { Mot_ex1 } \\
\text { Mot_ex2 } \\
\text { Overall_ME } \\
\text { Mental_contr_num } \\
\text { Mental_contr_days } \\
\text { Overall_mental_contr }\end{array}$ \\
\hline $\begin{array}{l}\text { Praxis (visio-constructive ability, } \\
\text { imitation of postures, ability to imitate) }\end{array}$ & $\begin{array}{c}\text { Constructive praxis [57] } \\
\text { Imitation of bilateral postures [61] } \\
\text { Ideational praxis [57] } \\
\text { The last item has been replaced by } \\
\text { another, more familiar and recognizable } \\
\text { for the DS population. }\end{array}$ & $\begin{array}{l}\text { Constr_praxis } \\
\text { Imi_post } \\
\text { Ide_praxis }\end{array}$ \\
\hline Orientation (time, place, person) & $\begin{array}{l}\text { Orientation in person (ad hoc) } \\
\text { Orientation in space (ad hoc) } \\
\text { Orientation in time (ad hoc) }\end{array}$ & $\begin{array}{l}\text { OP } \\
\text { OS } \\
\text { OT }\end{array}$ \\
\hline Writing & Graphics & Graphics \\
\hline
\end{tabular}

The Cats-and-Dogs test, from the Cambridge Executive Functioning Assessment battery (CEFA) [31], was administered to assess response inhibition capacity. In the test, participants were asked to indicate images of a "cat" and a "dog". They were then asked to say "cat" when they were shown an image of a dog and vice versa. They received points for good performance in the second stage of the test. The values that participants could obtain ranged between 0 and 5, according to the response execution level.

The database consists of a table with 39 variables and 188 registers. Some fields contain missing data, labelled 999 or null. We show the number of values to recover in Table 2. 
Table 2. Description of the fields with missing values.

\begin{tabular}{|c|c|}
\hline Variable Name & Amount of Missing Information \\
\hline Spont_lang & 1 \\
\hline Direct_D & 2 \\
\hline Span & 6 \\
\hline Deno_obj_body & 1 \\
\hline Graphics & 6 \\
\hline Mem_ima & 1 \\
\hline Mem_recog & 1 \\
\hline Errors & 2 \\
\hline OV_comp & 1 \\
\hline WV_comp & 26 \\
\hline Mental_contr_num & 1 \\
\hline Mental_contr_days & 1 \\
\hline Overall_mental_contr & 1 \\
\hline Mem_verbal & 1 \\
\hline Imi_post & 8 \\
\hline $\mathrm{EF}$ & 4 \\
\hline Secs & 5 \\
\hline Raven & 3 \\
\hline Verbal_flu & 3 \\
\hline PPVT & 1 \\
\hline Clock_copy & 3 \\
\hline $\mathrm{ZEF}$ & 4 \\
\hline PE_EF & 4 \\
\hline Category_EF & 4 \\
\hline Category_EF_2 & 4 \\
\hline Z_secs_EF & 5 \\
\hline PE_secs_EF_2 & 5 \\
\hline Categories_secs_EF & 5 \\
\hline Categories_secs_EF_2 & 5 \\
\hline
\end{tabular}

In the same way, the procedure to convert the variable Cats-and-Dogs from an initial polychotomous domain to a dichotomous domain was to assign zero (0) to the values 0 , 1 , and 2 and one (1) to the values 3,4 , and 5 , since it is considered that between $0-2$ the performance is worse than from a value of 3 . This gives a binary response variable, whose behavior is determined by the binomial distribution.

\subsection{Methods}

This work proposes a machine-learning-based system for the automatic selection of the main attributes that best explain the Cats-and-Dogs response variable (EF). This variable plays a key role in the psychological scope for the study of cognitive disability in humans. Hence, a system composed mainly of three stages is proposed. Initially, it allows the recovery of the missing data in the database, removal of correlated variables and automatic selection of the most important variables. The following block diagram shows the proposed stages (Figure 1).

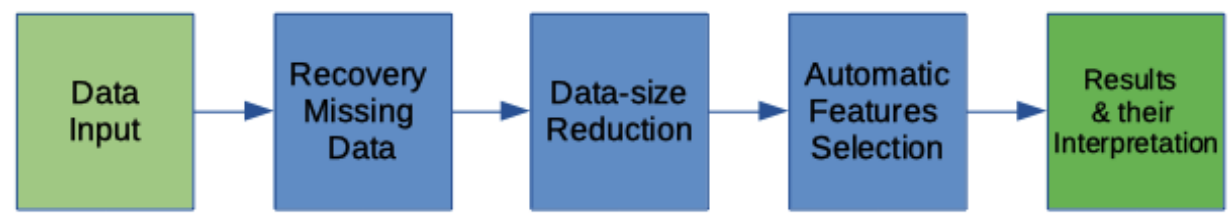

Figure 1. Block diagram of the proposed automatic variable selection model.

Machine learning is not the only approach that may be applied to these data in the study. We selected the approach that we thought was best suited to our multivariate dataset, 
because it is data driven and requires few decisions for selecting potentially predictive variables.

\subsubsection{Support Vector Machine as the Recovery Algorithm to Retrieve the Missing Data}

Data recovery uses related and independent data to recover the missing values with a machine learning algorithm [62]. For this task, a support vector machine was trained to carry out a regression [63], selecting the response variable as the one whose data were to be recovered, and the rest of the variables (with no missing data) as input variables. To measure the performance of the model for the data recovery task, we used the mean absolute percentage error [64] (MAPE), the mathematical expression of which is shown in Equation (1):

$$
\text { MAPE }=\frac{\sum \frac{\left(\text { real }_{i}-\text { Pred }_{i}\right)}{\text { real }_{i}}}{n} * 100 \%
$$

\subsubsection{Dimensionality Reduction Based on the Pearson Correlation Coefficient}

Based on [65], it is required that the input variables do not show correlation in a machine learning analysis in order to suppress disturbance and interference between them. Hence, we have obtained a Pearson correlation matrix per each field in order to select the variables that exceed one umbral. The following block diagram contains a description of each of the stages of the procedure (Figure 2).

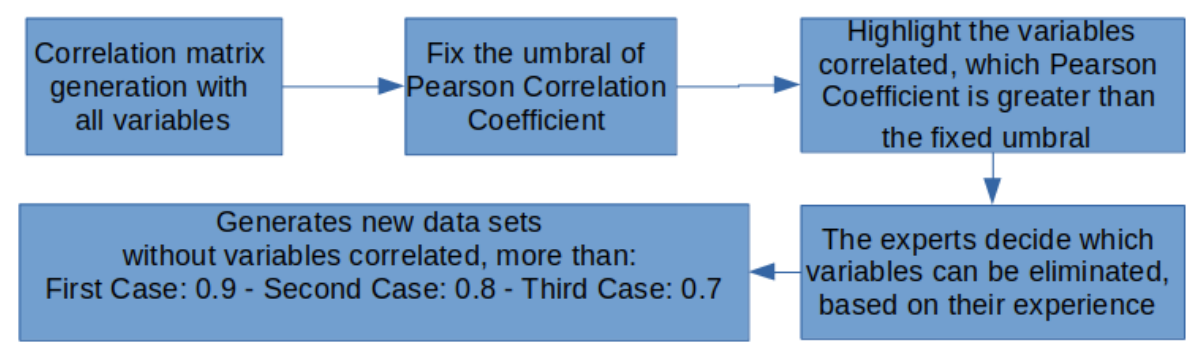

Figure 2. Block diagram of the steps to select the correlated variables.

\section{Correlation Matrix Generation with All Variables}

We built a Pearson correlation with all variables using the data described in Section 2.1. The purpose was to carry out a quantitative observation of the correlation between pairs of variables. This information was used to remove the redundant information in the training set of the machine learning models, in order to improve their performance.

Fixing the Pearson Correlation Coefficient Threshold

After discussion with experts, we proposed three threshold values, 0.7, 0.8, and 0.9, respectively, to obtain subsets of variables to be analyzed independently.

Highlighting the Correlated Variables

The correlated variables could be removed once their absolute Pearson correlation exceeded the threshold set by the researchers. Therefore, highlighting them facilitates the task of the selection and removal of variables, based on the researchers' knowledge of psychology.

\section{Variable Elimination by Experts}

The variables marked in the previous step were carefully revised by the experts, mainly taking into account their psychological significance. Once they were studied, the ones that should be removed to reduce the size of the dataset in terms of number of variables were identified. 
Generation of New Databases to Perform the Analysis

Finally, three datasets were obtained. These datasets were the ones used for the automatic selection of variables, applying the Random Forest, logistic regression, and support vector machine algorithms, as described in the following subsections.

\subsubsection{Automatic Variable Selection Algorithms}

The variable selection algorithms applied were based on three metrics which are widely used in the state of the art: entropy, logarithmic probability, and margin optimization coefficients. Each of them are described below:

\section{Random Forest as the Variable Selection Algorithm (RF)}

The Random Forest is an ensemble of decision trees [66] through the technique called bagging, in order to increase the generalization capacity and decrease the variance for the desired performance metrics, with the purpose to select, in an objective manner, the variables that impact the prediction of the output Cats-and-Dogs. This approach works by calculating the entropy [67] of the data for each tree and using them to determine the variables that provide the most classification information.

$$
\text { Entropy }=-p_{i} * \log \left(p_{i}\right)
$$

The bagging [67] classifier proposes a meta-algorithm to combine machine learning algorithms in order to improve the metrics of the overall performance of the system used. The following block diagram shows the model used (Figure 3).

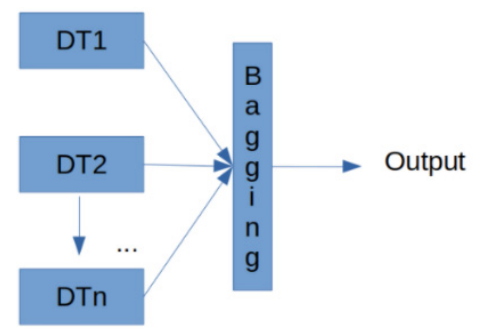

Figure 3. Model to detect the importance of the variables based on the decision trees used.

Each DTnblock corresponds to a decision tree trained with an independent part of the data, and their ensemble is performed in the last block, bagging in inference time to give a consensuated output.

Logistic Regression as the Variable Selector Algorithm (LR)

Logistic regression was used for this study, as the intention was to predict the Catsand-Dogs variable, and determine which variables interact most for its prediction.

It works by analyzing the output under a binomial distribution, as shown hereafter [68]

$$
Y \sim B\left(n_{i .} p_{i}\right)
$$

where $n_{i}$ corresponds to the number of Bernoulli trials and $p_{i}$ to the known probabilities. This enables us to obtain a list of logarithmic probabilities or Logits [68]

$$
\frac{p_{i}}{1-p_{i}}=e^{\left(b_{0}+b_{1} x_{1}+\ldots .+b_{j} x_{j}\right) ; \log i t_{\left(Y_{i}\right)}=\log \left(\frac{p_{i}}{1-p_{i}}\right)}
$$

As can be seen in Equation (4), the incidence of $X_{i}$ array, of size $j$ variables, is represented as the logarithmic probabilities related to the occurrence of the output variable $Y_{i}$, which is dichotomous for this case. 
Support Vector Machines as the Variable Selection Algorithm (SVM)

The operation of the support vector machine is based on the margin maximization (distance between the support vectors and the data used) in order to draw a hyperplane that represents the training phase of the algorithm. In inference, the relative position of the individual vectors is compared to the hyperplane, and it is used to define the degree of membership to the set classes. Once the algorithm has been trained, it is possible to access the model weights [68]

$$
H=W^{T} * X+B
$$

$W^{T}$ is an array of vectors whose direction focuses towards the desired solution.

The importance of the characteristic can therefore be determined by comparing the size of these coefficients with each other. Hence, it is possible to identify the main characteristics used in the classification by observing the SVM coefficients and removing the ones that are not important (that have less variance).

Finally, the reduction in the number of variables in machine learning plays a key role, particularly when working with large datasets. In fact, it can accelerate training, avoid overfitting, and ultimately lead to better classification results thanks to noise suppression in the data.

\section{Feature Selection Committee of All the Algorithms}

Each of the described algorithms will return in its output the variables considered as the most important in relation to its operation metrics for the prediction of the Cat-and-Dog variable (EF). For this reason, the decision was made by selecting the common variables in the output of the three machine learning algorithms applied, in order to detect and mitigate the implicit algorithmic bias.

Feature Selection by Importance Index

Similar to the previous stage, the results of the three algorithms were taken into consideration to decide which variables were most important in predicting the Cat-andDog response variable. However, at this stage, the selection principle was different. Each algorithm gave us a score depending on the order of the output of the variables. This was performed to normalize the results in regard to the internal execution metrics of the machine learning algorithms applied. It is important to mention that the first 20 outputs of each algorithm were chosen strictly by order. Therefore, the score assigned ranged from 1 to 20 , with 1 point for the last variable and 20 points for the first output variable. Finally, the ones with the highest number of points were selected.

\section{Results}

\subsection{Data Recovery}

Table 3 shows the recovered data available for use when applying machine learning techniques.

Table 3. Data recovered from the database for machine learning analysis.

\begin{tabular}{cc}
\hline Description & Amount \\
\hline Total complete data & 7218 \\
Total data recovered & 114 \\
Total data available for processing & 7332 \\
Total variables & 39 \\
Total registers & 188 \\
\hline
\end{tabular}

Table 4 shows the errors obtained for the data recovery problem, for each of the variables to be recovered. The available data were split into $80 \%$ for training and $20 \%$ for testing to elaborate the following table. 
Table 4. Mean absolute percentage error, MAPE, obtained for the recovery of missing data with the test dataset.

\begin{tabular}{|c|c|c|}
\hline Variable Name & Amount of Recovered Data & $\begin{array}{l}\text { Mean Absolute Percentage } \\
\text { Error in Testing }\end{array}$ \\
\hline Spont_lang & 1 & $95.77 \%$ \\
\hline Direct_D & 2 & $98.61 \%$ \\
\hline Span & 6 & $99.06 \%$ \\
\hline Deno_obj_body & 1 & $95.27 \%$ \\
\hline Graphics & 6 & $99.68 \%$ \\
\hline Mem_ima & 1 & $96.3 \%$ \\
\hline Mem_recog & 1 & $99.9 \%$ \\
\hline Errors & 2 & $97.28 \%$ \\
\hline OV_comp & 1 & $97.62 \%$ \\
\hline WV_comp & 26 & $96.92 \%$ \\
\hline Mental_contr_num & 1 & $95.38 \%$ \\
\hline Mental_contr_days & 1 & $95.07 \%$ \\
\hline Overall_mental_contr & 1 & $96.67 \%$ \\
\hline Mem_verbal & 1 & $99.19 \%$ \\
\hline Imi_post & 8 & $98.56 \%$ \\
\hline EF & 4 & $95.61 \%$ \\
\hline Secs & 5 & $95.28 \%$ \\
\hline Raven & 3 & $97.44 \%$ \\
\hline Verb_flu & 3 & $96.49 \%$ \\
\hline PPVT & 1 & $95.13 \%$ \\
\hline Clock_copy & 3 & $96.84 \%$ \\
\hline $\mathrm{ZEF}$ & 4 & $98.69 \%$ \\
\hline PE_EF & 4 & $96.91 \%$ \\
\hline Category_EF & 4 & $96.38 \%$ \\
\hline Category_EF_2 & 4 & $99.98 \%$ \\
\hline Z_secs_EF & 5 & $95.56 \%$ \\
\hline PE_secs_EF_2 & 5 & $96.38 \%$ \\
\hline Categorias_secs_EF & 5 & $98.86 \%$ \\
\hline Categories_secs_EF_2 & 5 & $95.2 \%$ \\
\hline
\end{tabular}

Once the data recovery algorithms had been applied, the correlated variables were removed to avoid redundant information and thus improve the performance of the proposed machine learning models.

\subsection{Removal of Correlated Variables}

The removal of variables for thresholds $0.9,0.8$, and 0.7 are shown below (Table 5).

Table 5. Removal of variables based on the Pearson correlation coefficient.

\begin{tabular}{cccc}
\hline Threshold & Variable 1 & Variable 2 & Removed Variable \\
\hline \multirow{2}{*}{0.9} & OT & OS & OT \\
& $\begin{array}{c}\text { Mental_contr_num } \\
\text { Mental_contr_days }\end{array}$ & $\begin{array}{c}\text { Overall_mental_contr } \\
\text { Overall_mental_contr }\end{array}$ & $\begin{array}{c}\text { Mental_contr_num } \\
\text { Menta_contr_daysl }\end{array}$ \\
\hline \multirow{2}{*}{0.8} & mot_ex1 & Overall_ME & Mot_ex1 \\
& Mot_ex2 & Total_EM & Mot_ex2 \\
& auto_leng_total & auto_leng_months & auto_leng_months \\
\hline \multirow{2}{*}{0.7} & Age & Age_groups & Age_groups \\
& Direct_D & Span & Direct_D \\
& OS & OT & OT \\
& Total_O & OS & auto_leng_num \\
\hline
\end{tabular}


It is important to highlight that the number of removed variables is cumulative. In other words, the variables that correlated with lower Pearson threshold correlation coefficients are also removed from higher thresholds.

\subsection{Committee- or Intersection-Based Variable Selection}

The RF, LR, and SVM machine learning algorithms described above for the automatic selection of variables were run for each of the subsets obtained, with the variable removal criteria described in Section 3.2. Furthermore, the intersection was taken as the final result to reach consensus on the total results of all the algorithms. This result refers to the output variables common to the three machine learning techniques. Table 6 shows the results obtained.

Table 6. Automatic selection of variables important for EF prediction.

\begin{tabular}{ccc}
\hline $\begin{array}{c}\text { Variables Selected in the } \\
\text { Subset of Variables with } \\
<\mathbf{0 . 9} \text { Pearson Correlation } \\
\text { Tolerance between Variables }\end{array}$ & $\begin{array}{c}\text { Variables Selected in the } \\
\text { Subset of Variables with } \\
\mathbf{< 0 . 8} \text { Pearson Correlation } \\
\text { Tolerance between Variables }\end{array}$ & $\begin{array}{c}\text { Variables Selected in the } \\
\text { Subset of Variables with }<\mathbf{0 . 7} \\
\text { Pearson Correlation } \\
\text { Tolerance between Variables }\end{array}$ \\
\hline Imi_post & OV_compr & Overall_ME \\
Mem_verbal & Mem_verbal & OV_compr \\
Direct_D & Overall_mental_contr & Span \\
Constr_praxis & Direct_D & Clock_copy \\
Clock_copy & Constr_praxis & Const_praxis \\
Errors & Errors & Total_leng_auto \\
WV_compr & WV_compr & Ide_praxis \\
\hline
\end{tabular}

Each column of Table 6 shows the most important variables for each subset obtained after variable removal. These are the variables that most influence prediction of the EF variable (Cats-and-Dogs). In other words, they are the most important in explaining the value obtained in the response variable. We have selected the column corresponding to variables with $<0.8$ Pearson correlation, based on our experience and knowledge about the focus study area, taking into account that more cognitive functions are represented in this column. Therefore, the best variable predictors of inhibition capacity were functions related to praxis, memory, attention, executive functions, and language: oral verbal comprehension, verbal memory, overall mental control, direct digits, constructive praxis, errors of memory of images, and written verbal comprehension.

\subsection{Variable Selection Based on the Importance Index}

As in the above table, the decision was made to use the results of the three machine learning algorithms together; however, with the difference of assigning each feature a weight on a scale of 1 to 20 according to the importance it is given in each algorithm. In this way, the result of the importance given by each algorithm is consistent, as they use different metrics. For instance, we can observe two with a significant weight for individual algorithms and not just the intersection of the overall results. Table 7 shows the results obtained. 
Table 7. Automatic selection of variables important for EF prediction based on weights.

\begin{tabular}{cccccc}
\hline $\begin{array}{c}\text { Variables } \\
\text { with } \\
\text { Correlation } \\
\text { under 0.9 }\end{array}$ & Weight & $\begin{array}{c}\text { Variables } \\
\text { with } \\
\text { Correlation } \\
\text { under 0.8 }\end{array}$ & Weight & $\begin{array}{c}\text { Variables } \\
\text { with } \\
\text { Correlation } \\
\text { under 0.7 }\end{array}$ & Weight \\
\hline Constr_praxis & 56 & Constr_praxis & 56 & Constr_praxis & 48 \\
Mem_verbal & 45 & Mem_verbal & 46 & Mem_verbal & 40 \\
Direct_D & 45 & VW_compr & 41 & Clock_copy & 36 \\
OP & 32 & Raven & 33 & Mem_recog & 34 \\
Mem_recog & 32 & Direct_D & 33 & OP & 33 \\
Raven & 31 & Secs & 33 & Secs & 33 \\
Secs & 31 & OP & 32 & Raven & 32 \\
Age & 28 & Mem_recog & 29 & PPVT & 32 \\
PPVT & 26 & Age & 27 & Age & 29 \\
Total_denomin & 24 & PPVT & 26 & Spont_lang & 29 \\
Clock_copy & 24 & Total_denomin & 26 & Total_denomin & 27 \\
Verbal_flu & 23 & OS & 26 & Clock_order & 26 \\
VW_compr & 22 & Clock_order & 24 & Verb_flu & 25 \\
Clock_order & 22 & Verbal_flu & 24 & VW_compr & 24 \\
Imi_post & 19 & Imi_post & 19 & Imi_post & 19 \\
Spont_lang & 19 & Clock_copy & 18 & Ide_praxis & 19 \\
Imi_post & 19 & auto_leng_num & 17 & Overall_ME & 19 \\
auto_leng_num & 17 & Imi_post & 17 & OV_compr & 17 \\
Ide_praxis & 16 & Overall_EM & 16 & Span & 17 \\
Overall_ME & 16 & Ide_praxis & 14 & Gender & 15 \\
\hline
\end{tabular}

Regarding the weight of each attribute, the cognitive variables that best predict the inhibition capacity are first the constructive praxis, followed by verbal memory, verbal written comprehension, general cognitive performance, direct digits, response speed to inhibition capacity, orientation in person, memory of visual memories, age, vocabulary, denomination of images, orientation in place, clock test copy, and verbal fluency. Thus, these cognitive variables which best predict the inhibition capacity are related to praxis, memory, attention, executive functions, and language.

\subsection{Performance of the Algorithms When Classifying the EF Variable}

In order to observe and compare the performance of the machine learning models used in the classification of the binary variable EF (Cats-and-Dogs), the decision was made to train and test each of them. The data were split into $80 \%$ and $20 \%$, respectively, for the subsets obtained after the removal of variables (Table 8).

Table 8. Comparison of performance as regards the balanced accuracy of the models used.

\begin{tabular}{|c|c|c|c|c|c|c|c|c|c|}
\hline \multirow{2}{*}{$\begin{array}{l}\text { Model } \\
\text { Metric }\end{array}$} & \multicolumn{3}{|c|}{ Subset Variables Correlation $<0.7$} & \multicolumn{3}{|c|}{ Subset Variables Correlation $<0.8$} & \multicolumn{3}{|c|}{ Subset Variables Correlation $<0.9$} \\
\hline & Acc & F1 & AUC & Acc & F1 & AUC & Acc & F1 & AUC \\
\hline $\begin{array}{l}\text { Random } \\
\text { Forest }\end{array}$ & $73.6 \%$ & $68.0 \%$ & $74.4 \%$ & $86.8 \%$ & $82.5 \%$ & $87.0 \%$ & $84.2 \%$ & $81.0 \%$ & $85.4 \%$ \\
\hline $\begin{array}{l}\text { Logistic } \\
\text { regres- } \\
\text { sion }\end{array}$ & $71.0 \%$ & $61.5 \%$ & $63.3 \%$ & $73.6 \%$ & $66.1 \%$ & $69.6 \%$ & $71.0 \%$ & $67.0 \%$ & $77.0 \%$ \\
\hline $\begin{array}{l}\text { Support } \\
\text { vector } \\
\text { machine }\end{array}$ & $57.8 \%$ & $51.0 \%$ & $55.0 \%$ & $55.2 \%$ & $47.5 \%$ & $51.6 \%$ & $60.5 \%$ & $58.1 \%$ & $70.4 \%$ \\
\hline
\end{tabular}

As shown in Table 8, the model with the best performance was Random Forest, with a balanced accuracy of $86 \%$ for the dataset formed by all the variables, except those that show a Pearson correlation above the 0.8 threshold (metrics highlighted in bold font). It 
is also highlighted that the balanced accuracy metric was used for this application, so the dataset shows a considerable imbalance of $86 \%$, as regards the amount of data per class of the Cats-and-Dogs response variable.

\section{Discussion}

The results of the present study show that three machine learning algorithms convergently indicated that the best predictors of inhibition capacity, an executive function, in our population with DS spanning young adulthood and aging, were the cognitive domains of praxis, memory, attention, planning, and language.

Past work has established that response inhibition is a key element of executive function that helps people with DS adjust to the demands of their environment. Cognitive changes during aging in persons with DS are characterized by difficulties in working memory, sustained attention, planning, and inhibition capacity [69], and it is particularly important to conduct further study on their relation to other cognitive domains [44]. A deeper understanding of executive function performance in adults with DS, and of the factors that predict it, is necessary to develop training regimens that could improve inhibition capacity and self regulation, which is necessary to increase their quality of life $[26,30,43]$.

This study focused on determining how the neuropsychological assessment of cognitive performance during aging in persons with DS can help to predict inhibitory control capacity. The results demonstrate that, among the cognitive functions assessed in this population, the best predictors of inhibition performance, measured through the Cats-and-Dogs test, are constructive praxis, verbal memory, immediate memory, planning, and written verbal comprehension. This set of cognitive functions is also known to be most vulnerable to aging in persons with DS [15-20,70].

Our results reveal some important insights that are useful for informing which functions should be the focus of the early detection of age-related impairment and intervention strategies for people with DS. First, constructive praxis was the cognitive function that carried the most weight in the prediction of inhibitory control capacity. Along with perceptual-motor functioning, performance in constructional praxis tests requires the ability to plan and organize actions, which draws upon processes of executive function. Indeed, recent studies showed that both praxis and inhibitory capacity decline in aging [51,71]. Second, verbal short-term memory predicted inhibitory function. In previous studies, short-term memory decline was found to be more frequent in adults over 35, showing an earlier onset and faster progression [72-74]. Further, immediate memory, assessed with the Digit Span test, also predicted inhibition capacity. Short-term and immediate memory are good indices of attention, which is sensitive to age-related changes in adults with DS. It is important to note that sleep can affect attentional performance, and that such deficits could be related to sleep apnea, which is frequent in DS [26,75]. Third, planning, as measured by a clock drawing test, and written verbal comprehension were predictors, although with lower weights than praxis or memory. Both tests require some motor planning similar to constructional praxis, which was highly predictive of inhibition capacity. Verbal ability per se appears to be relatively stable in adults with DS until 40,50, or even 60 years of age. The decline in verbal skills seems similar to that of the elderly of the general population [76], although it appears to occur earlier in persons with DS $[40,77,78]$. Together, our results suggest that these cognitive functions, which reduced executive performance, could be the minimum set of neuropsychological assessment factors needed for the early detection of $\mathrm{AD}$ in adults with DS, and could be used as intervention targets for improving executive function performance [26].

Assessment is therefore vital to determining the progression of age-related cognitive deterioration.

The studies reviewed from the literature indicate that there is still relatively little research with conscientious follow-up on the cognitive changes in adults with DS and, more concretely, of their executive functions, as this assessment is a complex process. 
Nevertheless, we know that persons with DS show inhibitory control deficits, which makes it vital to gain a better knowledge of how to assess these types of functions in order to improve their quality of life $[32,33,37]$. In spite of having made progress in recent years, finding appropriate instruments adapted to their cognitive profile is a challenge and a barrier to the early detection of the cognitive changes associated with the onset of $\mathrm{AD}$. The assessment of poorer performance in executive functions is key to achieving early diagnosis, since recent studies show that early clinical onset of AD coincides with frontal symptoms and may precede memory loss in persons with DS [45]. Furthermore, inhibition capacity is vital to boosting cognitive performance adapted to one's environment and is a key element in self-regulation, together with other cognitive functions such as attention, memory, or communication capacity. These mechanisms are vital to functioning successfully in one's environment, as they enable the creation of strategies and resources for self-management [30].

Some limitations of this study must be noted. First, the lack of adequate information on each participant's degree of disability prevented accurate determination of the relationship between cognitive changes and autonomy in daily life, taking into account their level of dependency. Second, it is worth emphasizing that administering neuropsychological tests adapted to adults with DS for precise assessment of all their cognitive functions is difficult. Although considerable progress has been made in recent years in designing standardized neuropsychological assessment adapted to the adult population with DS, more progress needs to be made in the accurate evaluation of the changes in different cognitive domains during the aging process. Third, it would have been useful to include more measures of executive functions, apart from inhibition capacity. We did not include some measures (e.g., reverse digits) because of a floor effect. Fourth, the machine learning algorithms used to identify key factors assume a correlation between the response variable and the training variables. This relationship may be linear or nonlinear. Nonlinear algorithms such as Random Forest and logistic regression were used to ensure better results. However, for the support vector machine algorithm, a linear relationship was assumed, which may have biased the results. Lastly, the amount of available data for this study only allows analysis with traditional machine learning algorithms. This limitation thus raises a future line of research that requires gathering more data. In this manner, with a sufficiently large amount of data, deep-learning-based classification algorithms could be used, which would make the results more accurate.

\section{Conclusions}

Based on the results of this study, we can conclude that the application of artificial intelligence techniques to cognitive assessment data identified that the best predictors of inhibition capacity during aging in adults with DS were praxis, memory, attention, motor planning, and written language. In light of the importance of inhibition capacity for adapting to one's environment and optimizing performance in daily life activities, we suggest that these functions should be included in neuropsychological assessment protocols for adults with DS. Additionally, taking into account the importance of executive functioning in the early diagnosis of cognitive decline associated with AD onset, knowledge of inhibition capacity performance will aid in such early detection. These results also suggest targets for the application of cognitive stimulation strategies to boost cognitive reserve and prevent age-related cognitive deterioration in persons with DS. Our results also demonstate the utility of classical artifical intelligence methods for exploring small datasets for the identification of important variables or features in comparison to classical statistical methods.

Author Contributions: Conceptualization, M.G.-S., A.M.-Z., C.J.V., M.M.-S., M.G.-B. and O.B.-R.; Data curation, M.F.J.-A., S.S.-M. and O.B.-R.; Formal analysis, M.F.J.-A. and M.B.G.-Z.; Funding acquisition, M.B.G.-Z., O.B.-R., A.M.-Z., M.G.-B. and O.B.-R.; Investigation, S.S.-M., M.B.G.-Z. and M.G.-B.; Methodology, M.F.J.-A., S.S.-M., M.B.G.-Z., C.J.V., M.M.-S., M.G.-B. and O.B.-R.; Project administration, O.B.-R.; Resources, M.B.G.-Z.; Software, M.F.J.-A., M.B.G.-Z. and A.M.-Z.; Super- 
vision, M.B.G.-Z., A.M.-Z., C.J.V., M.G.-B. and O.B.-R.; Validation, M.F.J.-A., S.S.-M., M.B.G.-Z., M.G.-S., A.M.-Z., C.J.V., M.G.-B. and O.B.-R.; Visualization, M.M.-S., M.B.G.-Z., M.G.-S., A.M.-Z., C.J.V., M.G.-B. and O.B.-R.; Writing—original draft, M.F.J.-A., M.M.-S., M.B.G.-Z., M.G.-S., A.M.-Z., C.J.V., M.M.-S., M.G.-B. and O.B.-R.; Writing-review and editing, M.F.J.-A., S.S.-M., M.B.G.-Z., C.J.V., M.G.-B. and O.B.-R. All authors have contributed substantially to the work reported. All authors have read and agreed to the published version of the manuscript.

Funding: This research was funded by Aristos Campus Mundus Research Projects for the Year 2019 (Ramon Llull University, Deusto University and Georgetown University) (Grant Number: ACM2019_11).

Institutional Review Board Statement: The study was conducted according to the guidelines of the Declaration of Helsinki.

Informed Consent Statement: Informed consent was obtained from all subjects and family members involved in the study.

Acknowledgments: The authors acknowledge the Aura Foundation and all the institutions that participated in the study.

Conflicts of Interest: The authors declare no conflict of interest.

\section{References}

1. Bayen, E.; Possin, K.L.; Chen, Y.; de Langavant, L.C.; Yaffe, K. Prevalence of Aging, Dementia, and Multimorbidity in Older Adults With Down Syndrome. JAMA Neurol. 2018, 75, 1399-1406, PMCID:PMC6248113. [CrossRef] [PubMed]

2. Danés, C.F. Aspectos específicos del envejecimiento en el síndrome de Down. Rev. Méd. Int. Síndr. Down 2012, 16, 3-10. [CrossRef]

3. Head, E.; Silverman, W.; Patterson, D.; Lott, I.T. Aging and Down Syndrome. Curr. Gerontol. Geriatr. Res. 2012, 2012, 1-6. [CrossRef] [PubMed]

4. Lott, I.T.; Dierssen, M. Cognitive deficits and associated neurological complications in individuals with Down's syndrome. Lancet Neurol. 2010, 9, 623-633. [CrossRef]

5. Cipriani, G.; Danti, S.; Carlesi, C.; Di Fiorino, M. Aging with Down Syndrome: The Dual Diagnosis: Alzheimer's Disease and Down Syndrome. Am. J. Alzheimers Dis. Other Demen. 2018, 33, 253-262. [CrossRef]

6. Brown, R.; Taylor, J.; Matthews, B. Quality of life-Ageing and Down syndrome. Down Syndr. Res. Pract. 2001, 6, 111-116. [CrossRef]

7. Carmeli, E.; Kessel, S.; Bar-Chad, S.; Merrick, J. A comparison between older persons with down syndrome and a control group: Clinical characteristics, functional status and sensorimotor function. Down Syndr. Res. Pract. 2004, 9, 17-24.

8. Lin, J.D.; Lin, L.P.; Hsu, S.W.; Chen, W.X.; Lin, F.G.; Wu, J.L.; Chu, C. Are early onset aging conditions correlated to daily activity functions in youth and adults with Down syndrome? Res. Dev. Disabil. 2015, 36, 532-536. [CrossRef]

9. Stancliffe, R.J.; Lakin, K.C.; A Larson, S.A.; Engler, J.; Taub, S.; Fortune, J.; Bershadsky, J. Demographic Characteristics, Health Conditions, and Residential Service Use in Adults with Down Syndrome in 25 U.S. States. Intellect. Dev. Disabil. 2012, 50, $92-108$. [CrossRef]

10. Berzosa Zaballos, G. Las Personas con Sindrome de Down y sus Familias ante el Proceso de Envejecimiento; Real Patronato Sobre Discapacidad: Madrid, Spain, 2013.

11. Franceschi, C.; Garagnani, P.; Gensous, N.; Bacalini, M.G.; Conte, M.; Salvioli, S. Accelerated bio-cognitive aging in Down syndrome: State of the art and possible deceleration strategies. Aging Cell 2019, 18, e12903. [CrossRef]

12. Benejam, B. Síntomas de demencia en el síndrome de Down. Rev. Méd. Int. Síndr. Down 2009, 13, 18-21. [CrossRef]

13. Ghezzo, A.; Salvioli, S.; Solimando, M.C.; Palmieri, A.; Chiostergi, C.; Scurti, M.; Lomartire, L.; Bedetti, F.; Cocchi, G.; Follo, D.; et al. Age-related changes of adaptive and neuropsychological features in persons with Down Syndrome. PLoS ONE 2014, 9, e113111. [CrossRef]

14. Dalton, A.J.; Fedor, B.L. Onset of dyspraxia in aging persons with Down syndrome: Longitudinal studies. J. Intellect. Dev. Disabil. 1998, 23, 13-24. [CrossRef]

15. Flórez, J. La atención temprana en el síndrome de Down: Bases neurobiológicas. Rev. Síndr. Down 2006, 22, 132-142.

16. Jarrold, C.; Nadel, L.; Vicari, S. Memory and neuropsychology in Down Syndrome. Down Syndr. Res. Pract. 2008, 12, 68-73. [CrossRef]

17. Lanfranchi, S.; Toffanin, E.; Zilli, S.; Panzeri, B.; Vianello, R. Memory coding in individuals with Down syndrome. Child Neuropsychol. 2013, 20,700-712. [CrossRef]

18. Palmer, G.A. Neuropsychological profiles of persons with mental retardation and dementia. Res. Dev. Disabil. 2006, 27, 299-308. [CrossRef]

19. Roberts, L.; Richmond, J.L. Using learning flexibly and remembering after a delay: Understanding cognitive dysfunction in adults with Down syndrome. J. Intellect. Disabil. Res. 2018, 62, 521-531. [CrossRef] 
20. Startin, C.M.; Hamburg, S.; Hithersay, R.; Davies, A.; Rodger, E.; Aggarwal, N.; Al-Janabi, T.; Strydom, A. The LonDownS adult cognitive assessment to study cognitive abilities and decline in Down syndrome. Wellcome Open Res. 2016, 1, 11. [CrossRef]

21. Lao, P.J.; Betthauser, T.J.; Hillmer, A.T.; Price, J.C.; Klunk, W.E.; Mihaila, I.; Higgins, A.T.; Bulova, P.D.; Hartley, S.L.; Hardison, R.; et al. The effects of normal aging on amyloid- $\beta$ deposition in nondemented adults with Down syndrome as imaged by carbon 11-labeled Pittsburgh compound B. Alzheimer Dement. 2016, 12, 380-390. [CrossRef]

22. Pujol, J.; Fenoll, R.; Ribas-Vidal, N.; Martínez-Vilavella, G.; Blanco-Hinojo, L.; García-Alba, J.; Deus, J.; Novell, R.; Esteba-Castillo, S. A longitudinal study of brain anatomy changes preceding dementia in Down syndrome. NeuroImage Clin. 2018, 18, 160-166. [CrossRef]

23. Licastro, F.; Porcellini, E. Individual Risk Detection of Developing Cognitive Decline and Dementia in Adults with Down's Syndrome. J. Down Syndr. Chromosom. Abnorm. 2017, 3, 117. [CrossRef]

24. McCarron, M.; Gill, M.; McCallion, P.; Begley, C. Health co-morbidities in ageing persons with Down syndrome and Alzheimer's dementia. J. Intellect. Disabil. Res. 2005, 49, 560-566. [CrossRef]

25. García-Alba, J.; Ramírez-Toraño, F.; Esteba-Castillo, S.; Bruña, R.; Moldenhauer, F.; Novell, R.; Romero-Medina, V.; Maestú, F.; Fernández, A. Neuropsychological and neurophysiological characterization of mild cognitive impairment and Alzheimer's disease in Down syndrome. Neurobiol. Aging 2019, 84, 70-79. [CrossRef] [PubMed]

26. McGlinchey, E.; Reilly, E.; McCallion, P.; Dunne, P.; Mulryan, N.; Carroll, R.; McCarron, M. Dementia and Intellectual Disability: Prevalence, Assessment and Post-Diagnostic Support. In Handbook of Intellectual Disabilities: Integrating Theory, Research and Practice; Matson, J.L., Ed.; Springer International Publishing: Cham, Switzerland, 2019; pp. 965-986. [CrossRef]

27. Miyake, A.; Friedman, N.P.; Emerson, M.J.; Witzki, A.H.; Howerter, A.; Wager, T.D. The Unity and Diversity of Executive Functions and Their Contributions to Complex "Frontal Lobe" Tasks: A Latent Variable Analysis. Cogn. Psychol. 2000, 41, 49-100. [CrossRef]

28. Casey, B.J.; Somerville, L.H.; Gotlib, I.H.; Ayduk, O.; Franklin, N.T.; Askren, M.K.; Jonides, J.; Berman, M.G.; Wilson, N.L.; Teslovich, T.; et al. Behavioral and neural correlates of delay of gratification 40 years later. Proc. Natl. Acad. Sci. USA 2011, 108, 14998-15003. [CrossRef]

29. Rosas, R.; Espinoza, V.; Garolera, M.; San-Martín, P. Executive Functions at the start of kindergarten: Are they good predictors of academic performance at the end of year one? A longitudinal study. Stud. Psychol. 2017, 38, 451-472. [CrossRef]

30. Petersen, I.T.; Hoyniak, C.P.; McQuillan, M.E.; Bates, J.E.; Staples, A. Measuring the development of inhibitory control: The challenge of heterotypic continuity. Dev. Rev. 2016, 40, 25-71. [CrossRef]

31. Ball, S.L.; Holland, A.J.; Treppner, P.; Watson, P.; Huppert, F. Executive dysfunction and its association with personality and behaviour changes in the development of Alzheimer's disease in adults with Down syndrome and mild to moderate learning disabilities. Br. J. Clin. Psychol. 2008, 47, 1-29. [CrossRef]

32. Bexkens, A.; Ruzzano, L.; Escury-Koenigs, A.M.L.C.D.; Van Der Molen, M.W.; Huizenga, H.M. Inhibition deficits in individuals with intellectual disability: A meta-regression analysis. J. Intellect. Disabil. Res. 2013, 58, 3-16. [CrossRef]

33. Kittler, P.; Krinsky-McHale, S.J.; Devenny, D.A. Verbal intrusions precede memory decline in adults with Down syndrome. J. Intellect. Disabil. Res. 2006, 50,1-10. [CrossRef] [PubMed]

34. Nelson, L.; Johnson, J.K.; Freedman, M.; Lott, I.; Groot, J.; Chang, M.; Milgram, N.W.; Head, E. Learning and memory as a function of age in Down syndrome: A study using animal-based tasks. Prog. Neuro-Psychopharmacol. Biol. Psychiatry 2005, 29 , 443-453. [CrossRef] [PubMed]

35. Oliver, C.; Holland, T.; Hall, S.; Crayton, L. Effects of Increasing Task Load on Memory Impairment in Adults with Down Syndrome. Am. J. Ment. Retard. 2005, 110, 339-345. [CrossRef]

36. Krinsky-McHale, S.J.; Devenny, D.A.; Kittler, P.; Silverman, W. Selective Attention Deficits Associated With Mild Cognitive Impairment and Early Stage Alzheimer's Disease in Adults with Down Syndrome. Am. J. Ment. Retard. 2008, 113, 369-386. [CrossRef]

37. Danielsson, H.; Henry, L.; Rönnberg, J.; Nilsson, L.-G. Executive functions in individuals with intellectual disability. Res. Dev. Disabil. 2010, 31, 1299-1304. [CrossRef]

38. Iacono, T.; Torr, J.; Wong, H.Y. Relationships amongst age, language and related skills in adults with Down syndrome. Res. Dev. Disabil. 2010, 31, 568-576. [CrossRef]

39. Burt, D.B.; Loveland, K.A.; Cleveland, L.A.; Lewis, K.R.; Lesser, J.; Pearson, P.L.; Primeaux-Hart, S. Comparing Dementia Diagnostic Methods Used with People with Intellectual Disabilities. J. Policy Pract. Intellect. Disabil. 2005, 2, 94-115. [CrossRef]

40. Das, J.; Divis, B.; Alexander, J.; Parrila, R.; Naglieri, J.A. Cognitive decline due to aging among persons with down syndrome. Res. Dev. Disabil. 1995, 16, 461-478. [CrossRef]

41. Beciani, S.; Vetro, E.; Barisnikov, K.; Detraux, J.-J.; Van der Linden, M. Elaboration d'une batterie d'évaluation des signes du vieillissement dans la trisomie 21. Rev. Francoph. Défic. Intellect. 2011, 22, 129-140.

42. Tomaszewski, B.; Fidler, D.; Talapatra, D.; Riley, K. Adaptive behaviour, executive function and employment in adults with Down syndrome. J. Intellect. Disabil. Res. 2018, 62, 41-52. [CrossRef]

43. Iralde, L.; Roy, A.; Detroy, J.; Allain, P. A Representational Approach to Executive Function Impairments in Young Adults with Down Syndrome. Dev. Neuropsychol. 2020, 45, 263-278. [CrossRef]

44. Loveall, S.J.; Conners, F.A.; Tungate, A.S.; Hahn, L.; Osso, T.D. A cross-sectional analysis of executive function in Down syndrome from 2 to 35 years. J. Intellect. Disabil. Res. 2017, 61, 877-887. [CrossRef] 
45. Lautarescu, B.A.; Holland, A.J.; Zaman, S.H. The Early Presentation of Dementia in People with Down Syndrome: A Systematic Review of Longitudinal Studies. Neuropsychol. Rev. 2017, 27, 31-45. [CrossRef]

46. Margallo-Lana, M.L.; Moore, P.B.; Kay, D.W.K.; Perry, R.H.; Reid, B.E.; Berney, T.P.; Tyrer, S.P. Fifteen-year follow-up of 92 hospitalized adults with Down?s syndrome: Incidence of cognitive decline, its relationship to age and neuropathology. J. Intellect. Disabil. Res. 2007, 51, 463-477. [CrossRef]

47. Carr, J.; Collins, S. Ageing and Dementia in a Longitudinal Study of a Cohort with Down Syndrome. J. Appl. Res. Intellect. Disabil. 2014, 27, 555-563. [CrossRef]

48. Temple, V.; Jozsvai, E.; Konstantareas, M.M.; Hewitt, T.-A. Alzheimer dementia in Down's syndrome: The relevance of cognitive ability. J. Intellect. Disabil. Res. 2001, 45, 47-55. [CrossRef]

49. Tungate, A.S.; Conners, F.A. Executive function in Down syndrome: A meta-analysis. Res. Dev. Disabil. 2021, 108, 103802. [CrossRef]

50. Li, B.; Fu, L. Exact test of goodness of fit for binomial distribution. Stat. Pap. 2018, 59, 851-860. [CrossRef]

51. Signo, S. The aging Process in People with Down Syndrome: A Multicenter Study to Detect Neuropsychological Changes. Ph.D. Thesis, University Ramon Llull, Barcelona, Spain, 2020. Available online: https://www.tesisenred.net/handle/10803/3527 12\#page=1 (accessed on 12 April 2021).

52. World Medical Association. Helsinki Declaration. Ethical Principles for Medical Research Involving Human Subjects; World Medical Association: Helsinki, Finland, 2008.

53. Raven, J.C. Test de Matrices Progresivas a Color; TEA Ediciones: Barcelona, Spain, 1996.

54. Folstein, M.F.; Folstein, S.E.; McHugh, P.R. "Mini-mental state": A practical method for grading the cognitive state of patients for the clinician. J. Psychiatr. Res. 1975, 12, 189-198. [CrossRef]

55. Kaufman, A.S.; Kaufman, N.L. Batería de Evaluación de Kaufman para Niños (K-ABC); TEA Ediciones: Madrid, Spain, 1997.

56. Dunn, L.M.; Dunn, L.M.; Arribas, D. Peabody. Test de Vocabulario en Imágenes; (PPVT-III); TEA Ediciones: Madrid, Spain, 2006.

57. Peña-Casanova, J. Programa Integrado de Exploración Neuropsicológica_PIEN: "Test Barcelona"; Masson: Barcelona, Spain, 1991.

58. Kirk, S.A.; McCarthy, J.J.; Kirk, W.D. ITPA. Test Illinois de Aptitudes Psicolingüísticas; TEA Ediciones: Madrid, Spain, 1996.

59. Gerstadt, C.L.; Hong, Y.J.; Diamond, A. The relationship between cognition and action: Performance of children $31 / 2-7$ years old on a Stroop-like day-night test. Cognition 1994, 53, 129-153. [CrossRef]

60. Cacho, J.; García, R.; Arcaya, J.; Vicente, J.L.; Lantada, N. Una propuesta de aplicación y puntuación del test del reloj en la enfermedad de Alzheimer. Rev. Neurol. 1999, 28, 648-655. [PubMed]

61. Bergès, J.; Lézine, L. Test de Imitación de Gestos; Masson: Barcelona, Spain, 1975.

62. Al-Tashi, Q.; Abdulkadir, S.J.; Rais, H.M.; Mirjalili, S.; Alhussian, H. Approaches to Multi-Objective Feature Selection: A Systematic Literature Review. IEEE Access 2020, 8, 125076-125096. [CrossRef]

63. Smola, A.J.; Schölkopf, B. A tutorial on support vector regression. Stat. Comput. 2004, 14, 199-222. [CrossRef]

64. Cutler, A.; Cutler, D.R.; Stevens, J.R. Random forests. In Ensemble Machine Learning, 2nd ed.; Zhang, C., Ma, Y.Q., Eds.; Springer: New York, NY, USA, 2012; pp. 157-175. [CrossRef]

65. Hall, M.A. Correlation-Based Feature Selection for Machine Learning. Ph.D. Thesis, Department of Computer Science, University of Waikato, Hamilton, New Zealand, 2020.

66. González, S.; García, S.; Del Ser, J.; Rokach, L.; Herrera, F. A practical tutorial on bagging and boosting based ensembles for machine learning: Algorithms, software tools, performance study, practical perspectives and opportunities. Inf. Fusion 2020, 64, 205-237. [CrossRef]

67. Tranmer, M.; Elliot, M. Binary Logistic Regression; The Cathie Marsh Centre for Census and Survey Research: Manchester, UK, 2020.

68. Yang, J.-B.; Ong, C.-J. Feature Selection Using Probabilistic Prediction of Support Vector Regression. IEEE Trans. Neural Netw. 2011, 22, 954-962. [CrossRef]

69. Lanfranchi, S.; Jerman, O.; Pont, E.D.; Alberti, A.; Vianello, R. Executive function in adolescents with Down Syndrome. J. Intellect. Disabil. Res. 2010, 54, 308-319. [CrossRef]

70. Dalton, A.J.; Mehta, P.D.; Fedor, B.L.; Patti, P.J. Cognitive changes in memory precede those in praxis in aging persons with Down syndrome. J. Intellect. Dev. Disabil. 1999, 24, 169-187. [CrossRef]

71. Koehl, L.; Harp, J.; Van Pelt, K.L.; Head, E.; Schmitt, F.A. Longitudinal assessment of dementia measures in Down syndrome. Alzheimers Dement. 2020, 12, e12075. [CrossRef]

72. Lockrow, J.P.; Fortress, A.M.; Granholm, A.-C.E. Age-Related Neurodegeneration and Memory Loss in Down Syndrome. Curr. Gerontol. Geriatr. Res. 2012, 2012, 463909. [CrossRef]

73. Tyrrell, J.; Cosgrave, M.; McCarron, M.; McPherson, J.; Calvert, J.; Kelly, A.; McLaughlin, M.; Gill, M.; Lawlor, B.A. Dementia in people with Down's syndrome. Int. J. Geriatr. Psychiatry 2001, 16, 1168-1174. [CrossRef]

74. Firth, N.C.; Startin, C.M.; Hithersay, R.; Hamburg, S.; Wijeratne, P.A.; Mok, K.Y.; Hardy, J.; Alexander, D.C.; Strydom, A.; The LonDownS Consortium; et al. Aging related cognitive changes associated with Alzheimer's disease in Down syndrome. Ann. Clin. Transl. Neurol. 2018, 5, 741-751. [CrossRef]

75. Ashworth, A.; Hill, C.M.; Karmiloff-Smith, A.; Dimitriou, D. The Importance of Sleep: Attentional Problems in School-Aged Children With Down Syndrome and Williams Syndrome. Behav. Sleep Med. 2014, 13, 455-471. [CrossRef]

76. Rondal, J.; Comblain, A. Language in ageing persons with Down syndrome. Down Syndr. Res. Pract. 2002, 8, 1-9. [CrossRef] 
77. Ribes, R.; Sanuy, J. Declive cognitivo en memoria y lenguaje: Indicadores del proceso de envejecimiento psicológico en la persona con síndrome de Down. Rev. Sindr. Down 2000, 17, 54-59.

78. Rondal, J.A. Dificultades del lenguaje en el síndrome de Down: Perspectiva a lo largo de la vida y principios de intervención. Rev. Sindr. Down 2006, 23, 120-128. 